\title{
Research of Language Ecological Crisis and Its Regulation Policy on Internet Context
}

\author{
Hongmei Zhu ${ }^{1}$ \\ ${ }^{1}$ Xi'an Fanyi University, Xi'an, Shaanxi, 710105 \\ 54892713@163.com
}

Keywords: Internet Context; Language Ecological Crisis; Regulate Policy

\begin{abstract}
As the Internet continues to deepen the depth and breadth of the ecological crisis are increasingly apparent language. Especially with more and more obvious language seeks to occupy an increasingly important position. The emergence of a variety of languages ecological problems is break the original balance of the ecological system language is the language of our ecological challenge, gradually lead to become a national language ecological crisis. This paper analyzes the current situation of the language ecological crisis in the Internet Context describes the ecological environment on the basis of language, to make a few specifications from the current status quo in the policy aims to regulate the language development of the Internet in the context of the current proposed some reliability Suggest.
\end{abstract}

\section{Introduction}

Language ecosystems and environmental and ecological systems have certain similarities, and even can be said that the ecosystem is the human language give insight based on environmental and ecological systems. Human destruction of natural ecosystem is the language so that people become increasingly concerned about the ecosystem. Since the language of ecology have been proposed, attention to language ecology of the world is increasing. A completes robust language ecology is the coexistence of various languages and social environment interactions while a dynamic equilibrium, which contains a variety of different languages to promote human development and exchange has a positive meaning.

\section{Ecological Environment Language}

Language ecological environment is developed on the basis of the natural ecology of this language as the core, resulting in language, existence, development, and the role of regulatory constraints and the disappearance of such a process plays such a complete system process language is the ecological environment. A complete language ecological environment contains the prerequisites for the existence of a language, to some extent in relation to any one of the factors affecting the ecological environment influence the language of a national language and the possibility of the existence of continuity there. Due to various factors make the language more and more obvious ecological problems, and gradually spread to become a language ecological crisis. Once a complete language of ecological environment changes, it will inevitably affect the language, a direct result of the survival of the state languages of imbalance.

\section{Situation Language Ecological Crisis under Internet Context}

Exchange and dissemination of science and technology, especially the rapid development of the growing popularity of the Internet and communication, all kinds of public media penetration in society, deepening it so that the contact between different languages and language, the influence becomes more in-depth and wide-ranging. In this state of rapid development of technology, especially in some minority languages face greater challenges, it affected the whole environment, and communication needs, naturally choose to use more powerful language, this neglect of native 
language makes Language ecological imbalance. In this one, is the Internet, science and technology, communication has played a role in boosting [2].

English is the official language used by most country. English is the world's most widely used second language is the official language of the European Union, international organizations and most Commonwealth countries. English is also the most closely connected with the computer language, most programming languages and English are linked, and with the use of the network, so that more universal use of English. This popularity of non-English speaking country's national language had a definite threat [3]. Even so, but most people do not really recognize the balance of the world's linguistic diversity is being broken. From the aspect of profit analysis, in order to respect the whole world exchanges, the role of universal use of English language in a certain extent, promote the exchanges between people, but the spread of English has been a threat to the many ethnic languages and native language. According to a research survey report shows that the world's surviving language in the 21st century will be more than half dying; 200 years later, more than 90 percent of the language will be gone. Our language although not globally endangered languages hotspot areas, but at least there are dozens of languages is in endangered status, such as Manchu, She makes language, Tatar, have already in a state of complete loss of communicative function, such as anger language, Gelo language, Pumi language, keno language, have already endangered. It makes more obvious boost Internet [4] our language ecological crisis.

The consequent emergence of the Internet is the Internet language, networks continue to penetrate into people's language calendar life, they influence play out the positive and negative role has become increasingly evident. Network language even has replaced part of people's daily life language, to a certain extent, changed the up thinking.

The birth of new media in the Internet is constantly destroying the original Chinese habits. In daily life, people often can see a variety of new word or phrase in the English crossed, this phenomenon not only in the Internet, and even appeared on television, radio, newspapers and magazines which, on Chinese habits wanton destruction reflected from the side of the Internet Context on Chinese habits are constantly permeate.

\section{Ecological Policy Specification Language Internet Context}

Strengthening the Normative Language Internet Context of Ecological Significance. As a special social resources, Language protection of indigenous languages in line with the development of society. China's current diversity of languages and dialects has caused widespread concern in the academic community and the general public. China has 56 ethnic groups, a total of over 80 languages, 30 languages. First, the language ecology strengthen regulate the Internet in the Context conducive to building a harmonious society and promoting common development among various peoples. Of belonging to a multi-ethnic, multi-lingual country, different languages there is a unified society, coupled with the impact of the Internet will certainly be a variety of problems, only to correctly handle the relationship between language and the language in relation to a certain extent developing countries and regions. Secondly, the Internet context language has a certain ecological environment research value, because in a way there have been some of China's endangered languages, these languages for the whole language of pedigree analysis, historical and cultural research has important significance, its value is not reflected in the language of the body, but also in terms of literature and anthropology. By standardizing the entire Internet context, to achieve the protection of the ecological environment of the language, effectively ensuring the correct language diversity, academic research, economic and cultural development has a very important role. Finally, through the standard Internet context favorite language ecological environment, to protect our language resources have a positive meaning [5]. Modernization and faster, this Internet ecology of language may influence more widely, how to avoid bad online language guide in the Internet environment, users have a correct language usage is having realistic.

Internet Context to Ensure Maximum Purity of the Language of Ecology. A national language represents a profound cultural and crystallization of the wisdom of the history of a country, but the context of the impact on Chinese language Internet more and more obvious, especially 
younger Internet users appear in the use of some of the more obvious aspects of the network terminology. Although a national language must be to ensure a certain degree of openness and diversity, which is consistent with the development needs of the language. But we must make the appropriate language control and this language of efforts to control the Internet should be more obvious. This is because taking into account the openness of the Internet apparent realization of the language active intervention, within a certain range to control the scope of the language of the convention.

Strengthen Macro-Control of the Internet Context. From an ecological point of view, mature language with a certain ecosystem is self-regulating control, through its own control to adjust again to reach a stable state.

First, strengthen Internet users a sense of crisis education. Language Ecological Crisis Awareness Education Internet community under the requirements of the power play by using various means of education create a certain environment, display the risk factors of the language, prompting the formation of Internet users a sense of crisis, so that in the face of bad network terms the process can consciously resist.

Second, to promote the Internet user can have a certain crisis of capacity. The first is the norm before the crisis stage, dynamic time supervision of the crisis, whether there is likely transformation. When a crisis occurs, Internet users can clearly understand the language crisis, and be able to do not participate in the public opinion, and reduce their role in the public opinion of. When a crisis occurs, the Internet users should consciously avoid participating in which, for example, the use of certain terms of a network, a national language of the ecosystem concept Internet users should avoid using the network words, reduce the spread of the network vocabulary.

Use the Internet to Build a National Language Database. By means of the advantages of the Internet we can create a national language holographic database, so the database can guide the development of China's Internet language correctly. With the role of traditional media and new media, including traditional media newspapers, television, etc., new media network media, etc., all kinds of modern methods of language will be stored in digital form. By building such a purpose language database it is to use the Internet to promote Chinese language habits of proper use. The introduction of the language policy of maintaining is a certain extent also the balance of the ecosystem language [6]. China's relevant laws and regulations identified by prohibiting any form of language form and hope through a variety of measures to gradually establish a management and supervision according to law language applications and social institutions and mechanisms language work effectively to achieve the popularity of Putonghua and standard Chinese characters and application level significantly improved purposes.

Establish a Correct Concept of Network Language. Internet context, new words, new sounds, new syntax, style, and so change the discourse faster Internet language use what attitude towards the Internet of a context. To be able to exclude part of the adverse effects, effectively ensuring the purity of the context of China's Internet, the guarantee open and tolerant attitude while appropriateness accept some new ingredients. This is because, according to the characteristics of the language in the new environment must be the emergence of new communication needs, plus the language itself has its own rules and characteristics of the structure, we need to do is level the specification of how to grasp. First, language policy, China has enacted relevant laws, but on the Internet involves the use of language is not much, and therefore how to strengthen this aspect of the legislation also requires sustained attention from the Government. Second, determine and ensure the status and authority of Mandarin, while the language of the network is to moderate interference tolerance policies can help develop a network of more positive language. Finally, in the context of the Internet were developed language policy of the government should strengthen behavior and effectively curb the spread of bad network terms.

\section{Conclusion}

Times are different depending on the language of ecological, social different, various factors such as the effects of different cultures exhibit different survival and development of the state. A 
good ecological environment of the language is to build a harmonious society locale important factor. Based on the analysis of the current status of the language in the Context of Ecological Crisis Internet on the basis put forward some targeted measures aimed to draw the attention of the masses in this regard and to actively participate in the community to build a good language environment in.

\section{Acknowledgements}

Project: Xi'an City 2013 annual social science planning fund project: "Chinese character standardization and Chinese International Education Research"; project number: XF111

\section{References}

[1] Yu Hui. How to Deal with Language Ecological Crisis Global Perspective. Social Sciences, 2008,13 (05): 171-173.

[2] Meng Xiangchun. World Languages Ecological Crisis In The Context Of Globalization. West Anhui University, 2009,11 (04): 121-124.

[3] Mei Deming. Ecological Study Language Big Data Era . Foreign Language Education, 2014,17 (01): 3-10.

[4] Xiang Huibin. From the Language Perspective Ecology See the Protection and Inheritance of Minority Languages. Hanshan Normal University, 2014,23 (05): 76-80.

[5] Fan Junjun. Crisis Minority Languages and Language of Human Rights Issues. Guizhou Ethnic Studies, 2006, 29 (02): 51-55.

[6] San Hui. Ecological Crisis of Chinese Thinking. Yangtze Normal University, 2007,29 (06): 118-121. 